\title{
Arrhythmia-induced cardiomyopathy: Case report
}

\section{Miocardiopatía inducida por arritmia: informe de caso}

\author{
Ana C. Gonzales-Luna',2*, Pedro Segura-Saldaña ${ }^{1,3,4}$, Rodrigo León-Vivar ${ }^{1,5}$, Jonny Laurente-Gómez \\ and Patricia Ríos-Navarro ${ }^{1,5}$ \\ ${ }^{1}$ Cardiology Department, Hospital Nacional Edgardo Rebagliati Martins; ${ }^{2}$ Clínica Delgado; ${ }^{3}$ Faculty of Biomedical Engineering, Universidad Peruana \\ Cayetano Heredia; ${ }^{4}$ Department of Cardiology Research, Torres de Salud National Research Center; ${ }^{5}$ Clínica Ricardo Palma. Lima Peru
}

Arrhythmia-induced cardiomyopathy (AICM) is a potentially reversible alteration, in which ventricular dysfunction is induced or mediated by atrial or ventricular arrhythmias. AICM early recognition and causal arrhythmia early treatment, with drugs or ablation techniques, result in symptom resolution and ventricular function recovery ${ }^{1}$.

\section{Clinical case}

The case of a 41-year-old male without previous known comorbidities, who was admitted to the emergency department for progressive dyspnea and a twoweek history of orthopnea, is presented. Upon admission, he was normotensive and had tachycardia, with signs of congestive heart failure and irregular heart sounds. Admission electrocardiogram (ECG) (Fig. 1A) documented atrial flutter with high ventricular response. He was administered intravenous amiodarone and lanatoside C, but developed QT interval prolongation (QTC, $550 \mathrm{~m})$ and had multiple episodes of ventricular fibrillation and helical tachycardia (torsades de pointes) that required defibrillation.

Echocardiogram revealed dilated cardiomyopathy (left ventricle [LV] diastolic diameter of $65 \mathrm{~mm}$, and left atrium, $50 \mathrm{~mm}$ ), with severe systolic dysfunction (LV ejection fraction of $28 \%$ ) and global hypokinesia.
Cardiac catheterization showed no coronary lesions. Electrophysiological study confirmed cavotricuspid isthmus-dependent atrial flutter (Fig. 1B and C), which underwent ablation and bidirectional block. The patient evolved favorably and was discharged under treatment with bisoprolol, enalapril and warfarin. Follow-up echocardiogram at four months showed reversal of cavities diameter and LV systolic function improvement (62\%) (Fig. 2). At one year of evolution, sinus rhythm has been preserved.

\section{Discussion}

AICM was first described in 1913, and its reversible nature was reported in $1962^{1}$. AICM is defined as left ventricular systolic dysfunction (LVSD) secondary to a pathological tachyarrhythmia (paroxysmal or persistent) or a very frequent atrial or ventricular ectopy ${ }^{1,2}$. AICM main characteristic is LV function recovery, either complete or partial, after arrhythmia suppression or control.

AICM incidence is also variable according to the type of arrhythmia; incidences ranging from $8 \%$ to $36 \%$ have been published with focal ectopic atrial tachycardia and from $9 \%$ to $34 \%$ with ventricular ectopy and non-sustained ventricular tachycardia. In the case of ectopic atrial tachycardia (EAT), Velásquez et al. reported 36\%
Correspondence:

*Ana C. Gonzales-Luna

E-mail: anace18@ hotmail.com
Available online: $20-10-2021$

\section{Arch Cardiol Mex (Eng). 2021;91(3):345-348
www.archivoscardiologia.com \\ Arch Cardiol Mex (Eng). 2021;91(3):345-348
www.archivoscardiologia.com} 2604-7063 / @ 2021 Instituto Nacional de Cardiología Ignacio Chávez. Published by Permanyer. This is an open access article under the CC BY-NC-ND license (http://creativecommons.org/licenses/by-nc-nd/4.0/).

Date of reception: 26-05-2020

Date of acceptance: 07-03-2021 


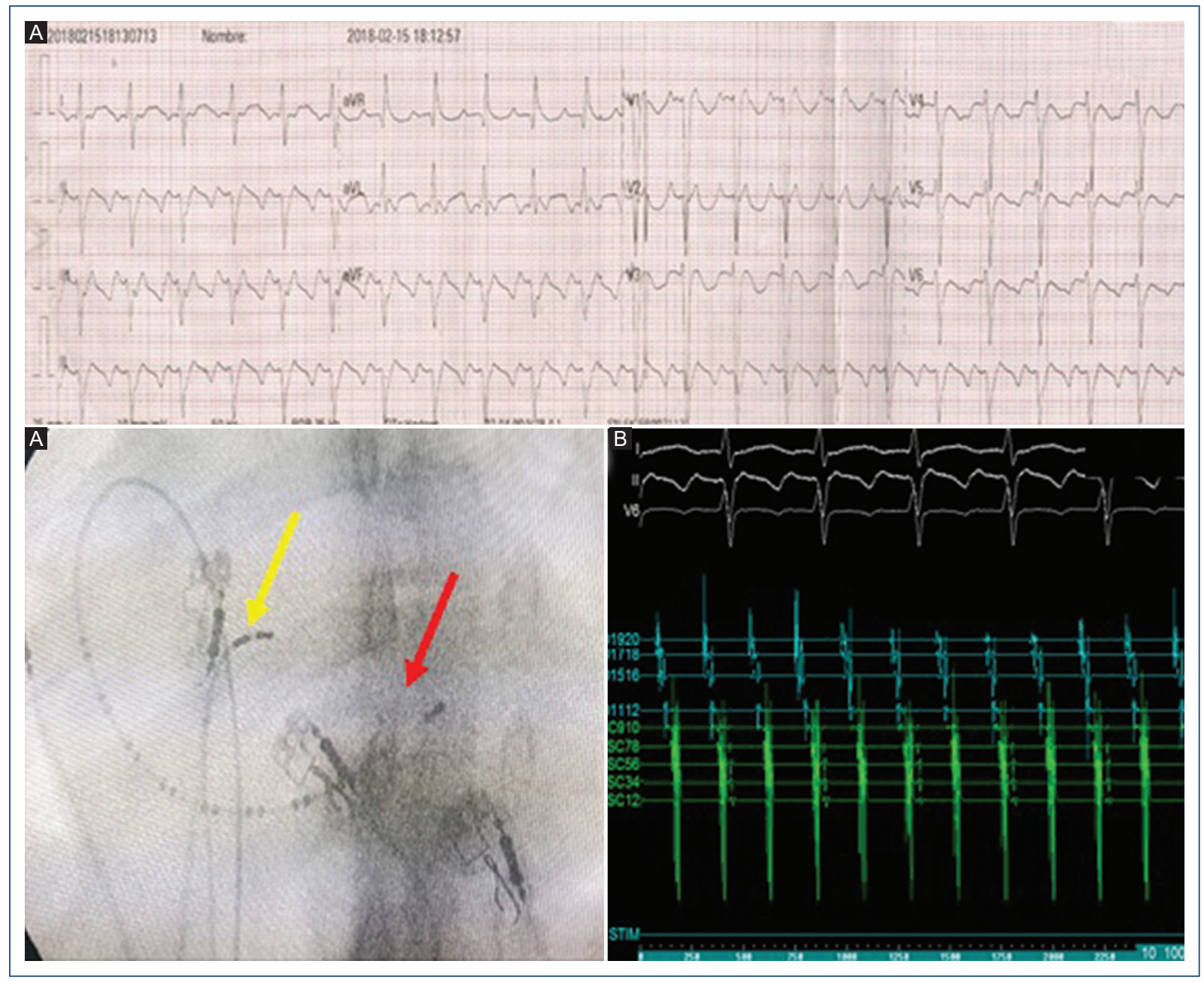

Figure 1. Echocardiography: long parasternal axis images. A: Echocardiographic study at patient admission; LV dilation is observed (end-diastolic and end-systolic diameter: $65 \mathrm{~mm}$ and $58 \mathrm{~mm}$, respectively). B: Control echocardiogram four months after ablation; reduction of both diameters is identified (end-diastolic diameter: $52 \mathrm{~mm}$; end systolic diameter: $35 \mathrm{~mm}$ ), with LV systolic function improvement.

with resistant EAT and $\mathrm{AICM}^{3}$. With atrial flutter, up to $25 \%$ has been described. In a study of 1,269 patients with atrial flutter, an incidence of AICM of $8 \%$ was found, as well as higher ventricular rates in comparison with LVSD from another cause (109 \pm 19 vs. $84 \pm$ $23 / \mathrm{min}$, respectively) ${ }^{4}$. The heart rate at which AICM starts being produced has been reported to be $>100$ beats per minute in a persistent manner.

Two types of AICM have been proposed:

- Type 1: arrhythmia-induced. Cardiomyopathy (CM) occurs de novo in a structurally normal heart and arrhythmia is the only cause. LV function normalizes after arrhythmia treatment ${ }^{2}$.

- Type 2: arrhythmia-mediated. Arrhythmia exacerbates pre-existing structural heart disease and arrhythmia treatment results in CM partial resolution?2.
Clinical presentation is variable, from asymptomatic cases $(10 \%)$ to end-stage heart failure (HF). Most commonly reported symptoms include palpitations (29\%), heart failure symptoms (47\%) and syncope or pre-syncope $(12 \%)^{5}$. Sudden death is uncommon, but it has been reported in up to $8 \%-12 \%$ despite AICM treatment and resolution ${ }^{6}$.

Symptoms appear at an earlier stage with higher HRs, as in persistent atrial flutter or tachycardia with 2:1 conduction ${ }^{6}$.

The diagnostic key is detection of arrhythmia in the presence of unexplainable LVSD. A single 12-lead ECG of may not diagnose the causal arrhythmia; ambulatory surveillance with Holter monitoring helps for recurrent tachycardia, mean ventricular rate in atrial fibrillation or flutter and frequency of premature ventricular complexes 


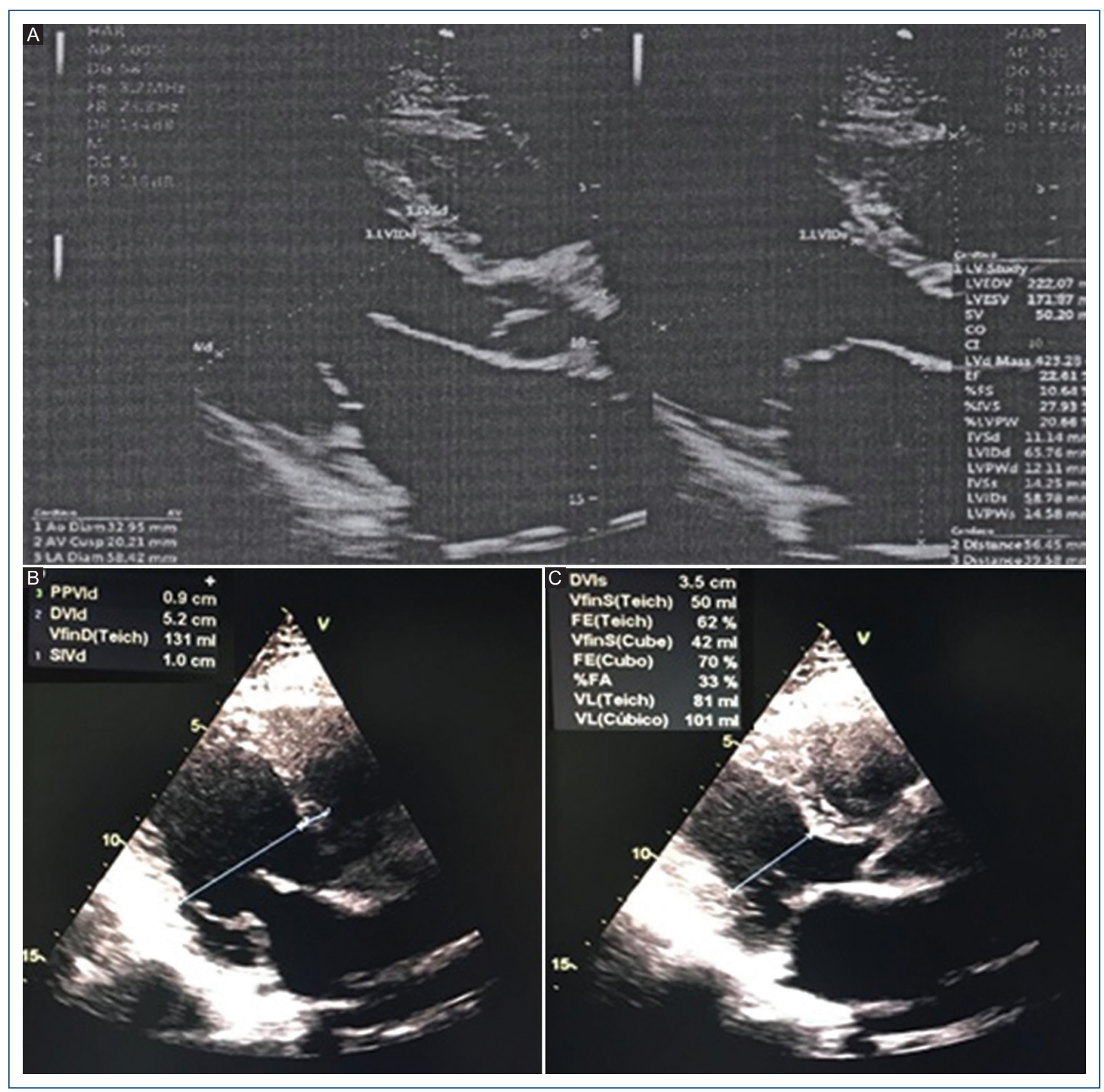

Figure 2. A: ECG outlines atrial flutter with 2:1 conduction, $136 \mathrm{bpm} \mathrm{HR}$ and negative $\mathrm{F}$ waves in leads II, III, aVF and positive in V1. B: Chest X-ray left anterior oblique projection showing a duo-decapolar catheter in mitral and tricuspid annuli (red arrow) and quadripolar catheter at the level of the His bundle (yellow arrow). C: Atrial flutter intracavitary registry on electrophysiological study. The first three channels are evidence of the surface electrocardiogram (leads I, II and V6) and the remaining channels are evidence of intracavitary electrocardiograms documented by the duodecapolar catheter: the five lower channels (green color SC1-2 to SC 9-10) register the signal at the level of the coronary sinus (mitral annulus) and upper channels (blue color SC11-12 to SC 10 -20) register the catheter in the right atrium (tricuspid annulus). Continuous activity is observed in these intracavitary electrocardiograms during atrial flutter.

to be identified ${ }^{1}$. Patients with AICM have lower end-diastolic LV diameter and LV mass index in comparison with those with preexisting dilated $\mathrm{CM}$.

Neuro-hormonal markers are elevated, according to the degree of HF, and their sudden decline within the first week after having eliminated or controlled the arrhythmia guides towards AICM diagnosis ${ }^{6,7}$. Correct diagnosis can only be established after demonstrating LV function improvement within a few weeks or months after arrhythmia treatment ${ }^{7,8}$.

In atrial flutter, controlling heart rate is often necessary, and electrical cardioversion is an effective 
method; given the risk of recurrence, catheter ablation is suggested as the treatment of choice, with a high success rate and few complications in typical atrial flutter, which in addition avoids drug toxicity ${ }^{2}$ (this patient had ventricular arrhythmia due to acquired QT prolongation). After atrial flutter ablation, patients with concomitant LVSD exhibit a LV function improvement in more than $50 \%$ of cases, and complete normalization is observed in nearly $75 \%$ of these patients ${ }^{4}$.

Although decisive treatment is arrhythmia control, disease-modifying drugs (angiotensin-converting enzyme inhibitors, beta-blockers, mineralocorticoid receptor antagonists) play an important role in remodeling reversal2,7.

\section{Conclusion}

Arrhythmias are a poorly recognized cause of LV systolic dysfunction. Although AF is the most common form of arrhythmia that causes AICM, atrial flutter is another of its main causes. Clinical and echocardiographic recovery after arrhythmia control confirms the diagnosis. Catheter ablation is the best therapeutic option, with symptom improvement and LV systolic function total or partial recovery; given its reversibility, treatment should be early implemented. There is risk of recurrence, and very close follow-up and radical treatment are necessary in case of recurrent arrhythmias.

\section{Funding}

This research has not received any specific grant from agencies of the public, commercial or non-profit sectors.

\section{Conflicts of interest}

None.

\section{Ethical disclosures}

Protection of human and animal subjects. The authors declare that no experiments have been performed on humans or animals for this investigation.

Confidentiality of data. The authors declare that they have followed the protocols of their work center on the publication of patient data.

Right to privacy and informed consent. The authors have obtained informed consent from the patients or subjects referred to in the article. This document is in the possession of the corresponding author.

\section{References}

1. Sugumar H, Prabhu S, Voskoboinik A, Peter M. Arrhythmia induced cardiomyopathy. J Arrhythmia. 2018;34:376-383.

2. Reyes-Caorsi W, Varela G, Tortajada G, Cortellezzi Z. Miocardiopatía inducida por arritmias. Revisión breve. Rev Urug Cardiol. 2019;34:122129 doi: 10.29277/cardio.34.1.21

3. Velázquez-Rodríguez E, Martínez-Enríquez A. Cardiomiopatía dilatada inducida por taquicardia auricular ectópica. Arch Inst Cardiol Méx. 2000;70:292-300.

4. Brembilla-Perrot B, Ferreira JP, Manenti V. Predictors and prognostic significance of tachycardiomyopathy: insights from a cohort of 1269 patients undergoing atrial flúter ablation. Eur $\mathrm{J}$ Heart Fail. 2016;18:394-401

5. Donghua Z, Jian $\mathrm{P}$, Zhongbo X. Reversal of cardiomyopathy in patiens with congestive heart failure secondary to tachycardia. J Interv Card Electrophysiol. 2013;36:27-32.

6. Huízar JF, Ellenbogen KA, Tan AY, Kaszala K. Arrhythmia-induced cardiomiopathy. JACC-state-of-the-art review. J Am Coll Cardiol. 2019;73(18).

7. Ulus T, Okyay K, Kabul HK, Özcan EE, Özeke Ö, Altay H. Turkish Society of Cardiology consensus paper on management of arrhythmia-induced cardiomyopathy. Anatol J Cardiol 2019;21:98-106.

8. Serra JL, Figueroa JA, Fassano N. Taquicardia auricular focal y taquimiocardiopatía. Rev Fed Arg Cardiol. 2018;47(1):03-09. 